\title{
Higher Education Institutions and Digital Practices in the Context of COVID-19
}

\author{
Jai Mohan Pandit ${ }^{*}$ and Bino Paul ${ }^{2}$ \\ 'Research Scholar, Tata Institute of Social Sciences, Mumbai - 400088, Maharashtra, India; jmpandit@igidr.ac.in \\ ${ }^{2}$ Professor, School of Management and Labour Studies, Tata Institute of Social Sciences, \\ Mumbai - 400088, Maharashtra, India; bino@tiss.edu
}

\begin{abstract}
Before the Novel Coronavirus outbreak (COVID-19), an open distance learning system was prevalent in India. Only a few institutions delivered education through digital or hybrid modes. However, with the onset of COVID-19, the digital mode of education has gained popularity, and its prevalence is now commonplace. There is no easy substitute for the digital mode of education and its adoption involves multilevel changes. This paper examines adoption of the digital mode of imparting education by Higher Education Institutions (HEI) in India. Web interviews were undertaken with principal stakeholders hailing from diverse sets of India's higher education institutions with the aim to understand in-depth, digital practices during COVID-19. Qualitative tools were used to analyse the data. The institutions found to be using heterogeneous ways to disseminate learning. While some of them practice a basic form of digitalisation, some had developed their own best practices. As a behavioural pattern, the development and prevalence of the digital mode may continue even post COVID-19. However, education through digital mode will persist to be plagued with challenges like digital divide.
\end{abstract}

Keywords: Higher Education Institution, COVID-19, Pandemic, Digital Systems

JEL classification: I15, I18, I23, O32 and O33

\section{Introduction}

The spread of COVID-19 during the first quarter of 2020 led to a multiphase lockdown in India ${ }^{1}$. Most of the Higher Educational Institutions (HEI) and their academic programs either got cancelled or deferred. As a result, it hampered the learning of over 320 million students in India ${ }^{2,3}$. It led to an impasse of delayed academic processes. Many institutions were on the verge of completing their academic processes. In the midst of all this, the outbreak of COVID-19 steered the acceleration of digital transformation worldwide $e^{4,5}$. Hence an option to mitigate the uncertainty of a prolonged stagnation was to adopt the digital mode for teaching and learning, examination, academic events, governance, and day to day administration $\underline{6,7,8}$.

Prior to the outbreak of COVID-19, very few HEIs adopted the digital mode for academic or administrative purposes. There has been digital initiatives by the Government of India like Study Webs of Active Learning for Young Aspiring Minds (SWAYAM)a) Massive Open
Online Courses (MOOC) for students and researchers (Swayam Central, 2021) , b) National Digital Library of India (National Digital Library of India, 2021) $)^{\frac{10}{}}$, c) Shodhganga (electronic repository of thesis), a digital initiative for enabling research scholars in India to deposit their thesis and also open access to the whole scholarly body (Shodhganga: A Reservoir of Indian Theses @ INFLIBNET, 2021)느, d) e-GyanKosh (eGyanKosh, 2021) $\frac{12}{12}$, e) Gyandarshan, (Gyandarshan, 2021) $)^{\frac{13}{3}}$, and f) e-Adhyayan (E-PGPathshala, 2021) ${ }^{14}$. Moreover, a flexible education system through open universities has also emerged. The Indira Gandhi National Open University (IGNOU) and many open universities cater to the broader range of learners. Another interesting variant is satellitebased education offered by management schools like the Indian Institute of Management (IIM).

However, these digital initiatives face constraints like course's quality, insufficient technological infrastructure, lack of funds, and geographical factors $\frac{15}{}$. Additionally, sudden shift from blackboard to the digital mode on a mass scale was abrupt and without proper planning, 
which created confusion among the students $\frac{16}{16}$. There was a discernable degree of confusion like, 'how to teach', 'what to teach' and 'when to teach', among the academia ${ }^{17}$.

The COVID-19 and the subsequent lockdown has impacted the functioning of HEIs in India to a great extent. Although a literature review reveals that the mass of HEIs faced severe difficulties, particularly in rural areas, a few responded to this crisis swiftly in the urban areas, mainly through the adoption of digital and online modes ${ }^{18,19,20}$. Majority of students in the rural areas, particularly those from lower socio-economic strata, faced problems like poor network connections, non-availability of laptops/ smartphones, and erratic supply of electricity ${ }^{21,22}$. These concerns are the primary causes of social distress and the digital divide in Indian HEIs.

The anxiety due to the pandemic has not only slowed the pace of students trying to pursue their careers but has also infused a significant level of stress and mental disorder among students ${ }^{23,24,25,26}$. A rise in mental health distress has been witnessed among students across HEIs in India ${ }^{27,228}$. The long break that COVID-19 brought along with it has led to considerable hindrance for student's academic growth and accomplishments, resulting in low self-esteem ${ }^{29,30}$. The indefinite lockdown has generated massive anxiety among students, particularly among

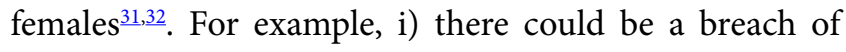
privacy, parents could easily snoop into the academic involvement at home ii) it is possible that female students are victims of domestic violence and sexual harassment attacks, and iii) due to the social distancing, many students were not able to travel to their native places or visit their relatives at the time of crisis, thereby being compelled to face loneliness. Along with loneliness, stress and pressure, students have also had to face lack of human touch and emotional support because of excessive dependence on online learning, thus amplifying their mental health

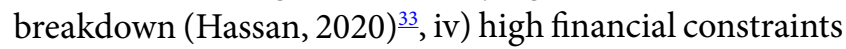
faced by low-income families (UNESCO IESALC, 2020). Loss of jobs has led individuals to close businesses consequently hindering them from providing for their children's college admission fees, suitable electronic gadgets for online study etc., adding to their anxiety levels. A few cases have resulted in children attempting suicide and becoming victims of either child marriage or joining their parents venture instead of pursuing their education ${ }^{34}$. The families who were drastically affected by the coronavirus,lost their dear ones, leaving behind their children had to face the trauma. Consequently, children had to drop out or leave their education in the middle to support their families, resulting in traumatic grief and upheavals in their academic lives. In addition to the students, faculty and staff have also had to face high levels of stress, which have resulted in anxiety, depression and other health-related issues ${ }^{35,36,37}$.

The digital divide, accompanied with new pedagogy challenges and related infrastructure requirements need top priority in the HEIs, since the COVID-19 may stay for some more time ${ }^{38}$. Digital technologies are apt to substitute the physical environment of classrooms, conferences, meetings and the library. The NEP 2020 has strongly argued for adapting digital and online systems in HEIs National Education Policy 2020 (MHRD, Govt. of India, 2020) $)^{39}$. Before COVID-19, HEIs were reluctant to use digital alternatives. However, the prevailing pandemic circumstances have pushed them from nascent to developing stages of digitalisation ${ }^{40}$. Some HEIs have moved to the system of malleable/open distance learning education, and it has brought new systems of governance in HEIs. Digital-oriented learning processes have emerged in HEIs at a considerable scale (Strielkowski, 2020)닐. Post COVID-19, higher education is likely to orient itself towards digital modes of learning, coordination and governance.

The literature also indicates that COVID-19 has generated various governance challenges for HEIs (Times Higher Education, 2021) ${ }^{42}$. The COVID-19 crisis has created an opportunity for leaders and management to take swift and vital decisions to ensure the smooth functioning of HEIs (Salmi, 2020) ${ }^{43}$. For instance, safeguarding the campus community from the risk of disease spread was one of the core challenges. Other significant concerns include: a) ensuring the continuation of learning through the digital mode, b) dealing with examinations, evaluations and submissions of Masters and $\mathrm{PhD}$ theses, c) counselling needs of the students, d) medical support, e) providing remote solutions to the students, and $\mathrm{f}$ ) support to students with teaching material $\underline{44,45,46}$.

Given that most of HEIs are residential, they have had the additional challenge of taking care of their employees, particularly their well-being (Gressman \& Peck 2020) ${ }^{47}$. The statutory bodies of HEIs, such as the governing board, academic council, finance committee, etc., were held on a virtual platform. Several HEIs organised convocations on a digital platform for the outgoing graduate students. Arranging these events required HEIs to work out new strategies to coordinate diverse activities and collective 
action by faculty, staff, students and other institutional stakeholders. For example, to ensure uninterrupted IT systems, IT staff had to envisage new service delivery models (Maqsood et al., 2021) ${ }^{48}$. During pandemic times, regular working hours were substituted by work from home that was not subject to any particular time limit. While many employees adapted to the change in work hours, others tried to learn techniques to cope with this change.

Babu and Ramaswamy (2021) discuss the issues related to higher education going online, particularly in the Indian context. They highlight the COVID-19 challenges and the digital divide faced by a majority of the HEIs in India. They argue that given the diversity of HEIs in, India the education system has given a heterogenous response to the pandemic. The results reflect the contrast in rural versus urban infrastructure. The authors highlight key recommendations of the New Education Policy (2020) which could benefit online/digital education through pilot studies for online education, augmenting digital infrastructure, online teaching platforms and tools, addressing digital divide, virtual labs, pedagogy and evaluation, and blended models of learning. According to Chakraborty et al., $(2021)^{\frac{49}{9}}$ students were better in the physical classrooms than the learning through digital modes. It reveals that a majority of students expressed their dissatisfaction with online teaching, although some were happy with the Massive Open Online Courses (MOOC) learning system. The authors do highlight that students somehow have expressed satisfaction with the efforts towards digital learning. The paper argues that digital divide has created anxiety among the students. The students felt that they learn better in physical classrooms (65.9\%) and by attending MOOCs (39.9\%) than through online education. The students, however, felt that the professors have improved their online teaching skills since the beginning of the pandemic (68.1\%) and online education is useful right now (77.9\%). The students appreciated the software and online study materials being used to support online education. However, the students felt that online education is stressful and affecting their health and social life.

Hassan (2020) finds that digital learning has emerged as a key tool to extend online learning to students. HEIs across the world including India, have moved to digital learning. Due to poor technological infrastructure and other constraints, the online mode has brought a major part of the country into a digital divide, more so in the rural areas, resulting in frustration, confusion and stress among students and parents. Providing online access to students at all levels has also been a huge challenge for educational institutions and regulators. The author argues that going forward, it is extremely important to understand the priorities of students and the challenges that they are confronting. According to Bordoloi et al., (2021), the concept of "one-size-fits-all" may not work in a country like India, where the challenges are humongous. Although developed countries may find it possible to impart online learning through the digital mode, the same may have many limitations in the Indian context where the digital divide between the rich and the poor, urban and the rural cannot be ignored.

Garg (2020) argues that the COVID-19 has had serious impacts on the HEIs in the country ${ }^{50}$. To begin with, it was a challenge for all concerned to understand how to proceed with the sudden online learning programme, in the absence of requisite digital infrastructure and related systems, which was the case in a majority of educational institutions in the country. Based on field studies in Ehiopia and India, Kummitha et al., (2020) $)^{51}$ report that most of HEIs are not equipped to provide digital teaching and learning activities to the students. The digital divide has been a major source of concern among institutions, the academia and students.

Rashid \& Yadav, (2020) discuss the impact of Covid19 on higher education, particularly the sudden closure of campuses and the adaptation of online systems to deliver classes $^{52}$. The move has seriously affected students in terms of affordability and accessibility alongwith requiring educators' training in digital technology. E-learning platforms and the role of the virtual environment in the current scenario may just become an integral part of the post-pandemic world's higher education system. In a similar vein, Strielkowski (2020) points out how the digital revolution in academia has taken centre stage owing to Covid-19. Otherwise, it would have taken many years for HEIs to implement and adopt such technology bases teaching-learning practices. Mittal (2020) highlights the impact of Covid-19 on the Indian higher education system in terms of admissions, classes, and placements. The paper shows evidence of a marked digital divide. The digital divide has created discrimination between urban and rural students, while there are few instances of HEIs setting examples of adapting to the situation. Their adaptation to the crisis reflects in their adoption of digital modes of learning and delivery systems (Jena, 2020) ${ }^{\frac{53}{3}}$. Aristovnik et al., (2020) ${ }^{\frac{54}{4}}$ discusses the impact of COVID- 
19 on aspects of students' lives globally pertaining to the beginning phase of 2020. The study argues that most students have been satisfied with the support provided by teaching staff and their universities during the worldwide lockdown as well as the transition to online learning. However, the students espressed concerned about issues pertaining to their future professional careers and studies as well as said that they experienced boredom, anxiety, and frustration.

According to Pandit (2021) $)^{\frac{55}{2}}$ the hybrid model would be there in higher education institutions as we progress. Indeed the online programs cannot replace physical campuses. "Students learn from teachers, learn from their batchmates and seniors through actual interaction. They also learn from students from other subjects by being present in the library, cafeteria, etc. So, while virtual teaching may extend the reach of only one source of learning, it compromises on the advantages of physical campus". Other extracurricular activities also play an essential role in the overall development of students. Full-time digital learning may be seen as an interim arrangement to mitigate the loss due to COVID-19 rather than an ideal system.

There are total 1043 university equivalent Institutions in India, including 48 Central Universities, 386 State Public Universities, 327 State Private Universities, 126 Deemed to be Universities, and 14 Open Universities (AISHE 2019-20) ${ }^{\frac{56}{6}}$. Universities include a) Central University: established by an Act in the Parliament of India b) State University: established by an Act in the State Legislature c) Deemed to be University: HEIs accorded the status of a university. They are authorised to award their own degrees, and d) Institutes of National Importance: reputable HEIs established by the Act of Parliament of India (Ministry of Education, 2021).

The Distance Education System began in India in 1962. There is one Central Open University, fourteen Open State Universities, and 1 State Private Open University. There are 110 Dual-mode Universities, which offer campus and distance education (AISHE, 2019-20) In 1991, the Distance Education Council (DEC) was established to coordinate and promote Indias open and distance learning system. The open and distance education system's regulatory aspect is with the University Grants Commission (UGC). The UGC is the apex regulatory and funding body for the Universities in India.

In this context, we conducted in-depth interviews with the core stakeholders of diverse sets of higher education institutions of India to understand a) the management of the overall functioning of HEI during the COVID-19 crisis and, b) the transformation of HEI from a conventional system to digital systems. As it was impossible to meet the individuals personally due to the ongoing pandemic, in-depth web interviews were conducted during September-December, 2020. Previous studies have not focused on the perception of the principal stakeholders of the HEIs regarding the impact of the COVID-19, which makes the study stand out.

\section{Methodology}

Qualitative research methods were used to study how HEIs have dealt with India's COVID-19 challenges and the valuable role digital systems have played. Qualitative research is a means for exploring and understanding individuals or groups ascribed to a social or human problem. The research process involves emerging questions and procedures, data typically collected in the participant's setting, data analysis inductively building from particulars to general themes, and the researcher making interpretations of the meaning of data. The qualitative research method was more suitable for the study as the data was collected in the natural setting (Creswell, 2017) ${ }^{\frac{57}{}}$. The researchers had used thematic analysis to analyse the data. Thematic analysis is one of the most common forms of analysis within qualitative research. It emphasises identifying, analysing and interpreting patterns of meaning (or "themes") within qualitative data (Braun \& Clarke, 2006) $)^{\frac{58}{}}$. The thematic analysis is defined as - 'analysis based on identifying themes in qualitative material' (Seale, 2004) ${ }^{59}$. Thematic analysis is an excellent approach to research where one is trying to find out something about people's views, opinions, knowledge, experiences or values from a set of qualitative data.

Given the pandemic situation and countrywide lockdown, it was challenging to collect the data in person. It was not possible to interview students and other stakeholders due to COVID-19 constraints hence we relied on the literature to understand concerns of multiple stakeholders, particularly learners. We collected the data through semi-structured interviews over the online platform from key stakeholders of HEIs. This allowed the participants to share their voices that the researcher used and interpreted. The key research questions asked during the web-based interviews are provided in Appendix 1. 
Figure 1 depicts the structure of the data analysis. We went through the video interviews several times. The transcript was prepared for each interview by using the Otter software. We cross-checked the videos and the transcript produced by the software and corrected the anomalies in the transcript.

Further, we coded the voices of participants which includes the process of organising the material into chunks or segments of text before bringing meaning to information (Rossman \& Rallis 1998) $\frac{60}{\text {. The coding }}$ process was used to generate a description of the setting or people as well as categories or themes for analysis. Two themes emerged from the analysis: Response to COVID19 crises and Importance of digital systems during COVID-19.

\section{Population and Sample}

The population of the study includes all the principal stakeholders of Higher Education Institutions. Principal stakeholders include the Vice-Chancellor/Director (Principal Executive Officer), Dean (Functional Head of the Academic Affairs), Registrar (Chief Administrative Officer) and Faculty members (Teachers) of Selected Higher Education Institutions in India. Nineteen HEIs were selected by using purposive sampling, covering 22 participants (Appendix 2). The sampling's objective was to have a representative mix of HEIs, absorbing prominent heterogeneities like ownership, size, location and age. The saturation in identifying new categories from the voices emerged by the $20^{\text {th }}$ interview. However, we interviewed two more participants to explore more voices. The sample appears to represent every stratum of HEIs in India, as shown in Table 1.

Table 1. Sample Size of the Higher Education Institution

\begin{tabular}{|l|l|l|}
\hline S. No. & Higher Education Institutes & Nos. \\
\hline 1 & Central University & 3 \\
\hline 2 & State University & 5 \\
\hline 3 & Institute of National Importance & 5 \\
\hline 4 & State Private University & 3 \\
\hline 5 & Deemed University & 3 \\
\hline & Total & 19 \\
\hline
\end{tabular}

Source: AISHE, 2019-20

\section{Findings}

We started the study with the questions listed in Appendix 1. Interviews generated two broader themes: a) Response to COVID-19 crisis and b) Digital solutions for i) teaching ii) examination \& evaluation and (iii) administration during the COVID-19 crisis.

\section{Theme 1: Response to Covid-19 crisis}

Most of the participants shared experiences about how they coped with the COVID-19 crisis through flexible governance and institutional systems.

After the Government announced the nationwide lockdown, academic activities in HEIs either got cancelled or postponed. HEIs began organising some academic activities online as transitioning to the digital mode was inevitable. The biggest challenge was to ensure that the students, faculty and staff had adequate connectivity and digital equipment. It also involved intense coordination with the students, faculty and staff. There were some instances of letting students continue on the campus given travel various constraints. However, a few HEIs found it complex to deal with the COVID-19 crisis due to their having had lesser engagement with digital systems for academic and administrative processes (Joshi et al., $2020)^{61}$.

A Vice-Chancellor narrates (VC-1 of a small-size HEI):

'We sent student's home. We took that initiative because it was essential. We also appointed a COVID-19 Committee based on UGC guidelines. The COVID-19 Committee had to meet frequently and took decisions on on-campus community-related issues'.

The voice reveals that the HEI took quick decisions to send students home, which helped students as well as the campus community to minimise the spread of the virus infection'on the campus. To tackle such an unprecedented situation, a majority of HEIs appointed internal COVID19/Task Force Committees. Such a Task Force Committee assisted the HEIs to take care of campus pandemic related issues. HEIs having residential campuses have had to face several challenges including provisioning of essential services. Such planning helped the HEIs to maintain the work force on the campus.

The HEIs had to face several other constraints, such as the enforcement of government and municipal orders. A participant (VC-2 of a medium-size HEI) said: 


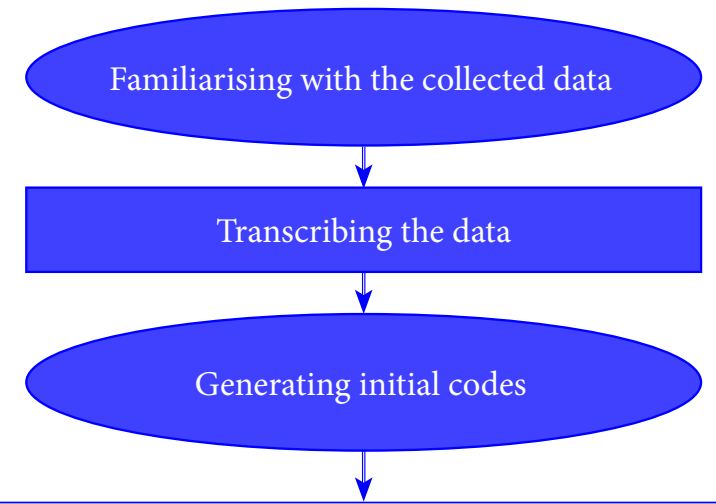

Initial response, Committee formation, New guidelines, Challenges, Online teaching, Collaboration with the State govt. Resource distribution, Swift response, Digital teaching, Remote access, Non-stop cooperation, Resource utilisation, Multi-taskingUsage of social media, Lack of technological awareness, Unlock phase, Awareness generation, Engaging in social welfare activities, Alternate teaching pedagogy, New evaluation methods, Challenges in a new pedagogy, Further initiative, Lack of infrastructure, lack of technological advancements, Lack of computer literacy, Lack of motivation for digitisation.Increase in efficiency through digitisation, Constrains of digitisation, Pros of digitisation's, Quick access, Swift management Smart classrooms- better exposure, New mode of teaching, Cost effective.

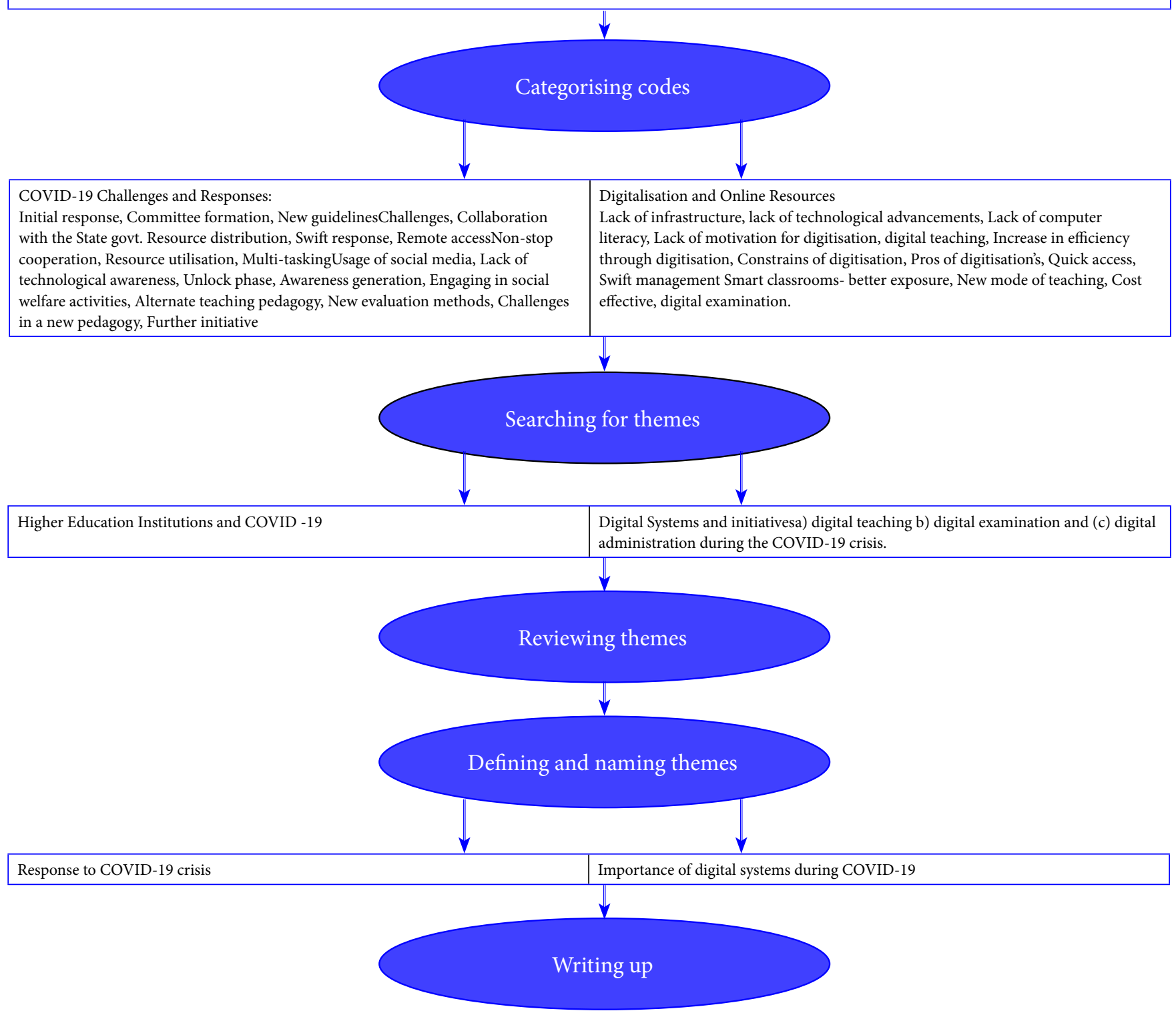

Figure 1. Structure of Thematic Analysis. 
'We had to comply with government guidelines on necessary precautions'.

The voice reveals that the HEI ensured the fulfillment of all government and local municipal guidelines.

Another critical concern for HEIs has been about testing and providing quarantine facilities for their internal campus community as well as the general public, while complying with mandates of the state. A participant (Registrar-2 of a large-size HEI) has shared:

'We had to share our facilities, such as hostels, vehicles and laboratory'.

Although the literature reveals that a majority of the HEIs and students faced problems particularly in rural areas, including a digital divide, there have also been a few instances of HEIs who could manage the smooth transition during the COVID-19 crisis. The key stakeholders, particularly that of the HEIs having a national presence or located in the metropolitan cities, viewed that they took quick decisions to adapt to diverse stakeholders' needs on the campus (Crawford, 2020). Therefore, they could oversee the coordination between institutional resources and desired outcomes. They also had flexible governance, automation, and digital systems, which became very convenient during crisis times. One participant (VC-3 of a large-size HEI) stated:

'We moved without losing a single day to online classes. There is no dilly-dallying about anything. So, we moved the library, clubs and societies online'.

Another participant (VC-4 of a large-size HEI) said:

'We have never suffered loss of teaching hours and everything went on smoothly'.

The participant further elaborated on how s/he managed multiple tasks in one go with flexible management systems. The participant commented:

'All the online forms were developed internally by our computer centre staff'.

What matters is leadership, training, support and motivation of the employees. Even in a crisis, leadership, humility and the willingness to help, plays a major role (UNDP, 2020) ${ }^{62}$.

Vice Chancellor-5 of a medium-size HEI commented:

'The moment students reached home, we immediately provided them with remote access, particularly to the library. Teachers were in regular contact with the students through emails and WhatsApp. We provided learning material online and coordinated the projects and vivavoice online'.
Another participant (VC-6 of a small-size HEI) viewed:

'We have accepted COVID-19 challenges, and could handle them well. Initially, total closure was there, but then we started online classes gradually. The students objected to it. Some students found it expensive to use the internet. We assured them that we would meet the expenses'.

The voice reveals that the HEI had challenges initially but gradually they were able to overcome all the challenges and started moving towards the online method of teaching and learning. The literature studied clearly reveals that, a majority of HEIs had to face such initial challenges to motivate their students and faculty to use digital tools. Indeed, there was no time for HEIs to provide proper training to their faculty and students. The participant then shared his/her experience regarding the problems in social distancing normson campus. For example, the participant highlighted that initially, nobody had planned such systems and structures for maintaining social distancing norms.

Another participant (Dean-1 of another large-sized HEI) said they had about 5400 (out of 8000) students on the campus before the lockdown. It was a massive challenge for them to take care of such a large group specially the need for human resources to support such a large gathering. It was also very difficult to motivate the staff to stay back and help. There was some resistance initially but with concerted efforts the staff was convinced. The participant remarked:

'We realised that some incentive scheme must be there to motivate the employees. So, we contacted our alumni for funds. We then provided financial support to the needy and also provided additional financial support to the faculty and staff'.

Generous support from the alumni and employees helped the HEI to manage and tide over the crisis. The voices reveal the complications faced by the HEI. The participant further narrated that the HEI had put sanitisation equipment all around the campus at various places and also ensured social distancing on the campus.

Registrar-3 of a medium-size HEI remarked:

'We took the swift decision to send all student's home. We did not delay for even a minute. By the time the lockdown happened, our students had safely returned home. The next thing was to enforce detailed protocols supported by a COVID-19 Task Force'. 
The voice reveals the swift action taken by the HEI to ensure smooth functioning. View of another participant (Dean-2 of a large-size HEI):

'The moment the lockdown was announced, we started teaching online. Frankly, we were not prepared. Some faculty members could do it effectively, while others could not cope with that. They could not make it interactive. Some senior faculty found it difficult in the beginning.

Even though the HEI started online teaching, the voice reveals the various complications that the HEI had to face. While a few faculty members could manage the transition to the digital mode, several others could not because of lack of knowledge and training in managing digital tools. In particular, the senior faculty found it extremely difficult to manage online teaching. The same is true for the students. As a result, such members of the faculty and students were forced to adapt to the online teaching/learning process under pressure.

Registrar- 4 of a large-size HEI, sounded very confident about how HEI dealt with the situation.

'Two days back, we opened the Institute making sure that only $50 \%$ of the staff are present at a time either on alternate days or half-day morning half-day after, and it depends on people how they will come. We had very strong online systems through MOOCs earlier. So, it is not a significant difficulty for us. Our servers are very powerful'.

Although very limited HEIs in the country have fullfledged infrastructure facilities to tackle the COVID-19 like crisis, there are a few examples particularly in the category of Institutions of National Importance like IITs who could manage the re-opening of the campuses to some extent efficiently. The voice suggested that the hybrid model (classroom and virtual) might stay for some more time.

Story shared by a participant (Dean-3 of a large-size HEI):

'At the very beginning, in March, just around the time when the lockdown was happening, we called the meeting of faculty and staff. We organised an event to disseminate the information on safety, social distancing, and hygiene. The communication was through multiple languages, including English, Hindi, and vernacular. It adopted the hybrid model ofwork from home and office.

\section{Theme 2: Importance of digital systems during COVID-19}

The second theme that emerged from the in-depth interviews is the importance of digital systems during COVID-19 and it further brought forth three sub themes. i) digital teaching ii) digital examination and (iii) digital administration. All the participants expressed the need for digital systems and their significance in the future.

i) Digital teaching:

A participant (FM-1 from a large-size HEI) commented:

'Reforms can be brought out by digitisation. That is not happening. It can play a crucial role in reducing inefficiency. Now, during COVID-19, teaching will go online. We are uncertain about how it will evolve.

The above voice indicates that there are HEIs who remain unprepared to adapt to changes like digitalisation. Systemic changes emanating from competition or regulation may likely push them to these changes (Rashid \& Yadav, 2020).

A participant (Reg-1 of a medium-size HEI) commented:

'We completely stopped the physical teaching and resorted to online teaching and evaluation. Since we have students are from various regions, there were variety of issues while imparting online teaching. For example, some students did not have internet connections or laptops etc.'

The voice reveals that some HEIs have students from different regions in India. While some regions' internet connectivity was good, it was a challenge in the other

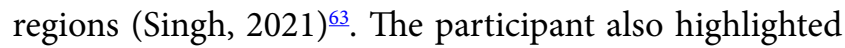
that some of the students did not have gadgets like laptops. Indeed several regions, families and students were confronted with the digital divide issues.

Another participant (Dean-3 of a large-size HEI) commented:

'We had set up online learning. It happened a lot more effectively than I anticipated'.

The voice seems to be satisfied with the digital learning initiative taken by the HEI.

The Vice Chancellor (VC-7) of a small-size HEI, mentioned that four activities formed the core of the work in his/her HEI, which included: a. Teaching, b. Research c. Research Projects d. Consultancy Projects. S/he further remarked: 
'Of these activities, teaching has suffered the most significant setback. Lack of direct student to teacher contact has meant that the 'silent majority' has not been able to keep pace with the bright minority, which does not rely on the teacher as much. Also, examination standards had to be lowered.

The participant further elaborated that research and research projects work suffered in the initial phase of the lockdown particularly from March 2020 to June 2020 (IAU 2020). After that, research activity recovered largely because it was most often done in small teams or individually. Simultaneously, consultancy projectshave come to a standstill chiefly due to the steep recession.

A participant Vice-Chancellor (VC-9) of a large-size HEI commented:

'Since every department of our University was already equipped with Digital and Smart Classrooms, the transition to an online mode was accessible. Moreover, every department is given the freedom to choose a licensed version of an online teaching platform to engage the classes online'.

The voice reveals the preparedness of the HEI towards adapting digital systems and its efficient transition to an online mode (Mishra, 2021) $)^{64}$.

Registrar (Reg-3) of a medium-size HEI indicated that the moment the students reached home, they realised that there is scope for online teaching and learning. So, they started online education within fifteen days, and completed the semester portions by May 31. The participant further commented:

'We are upgrading the learning infrastructure. Online teaching is possible from any of the classrooms. If faculty want to teach from their homes, we provide financial resources to buy software and equipment'.

Participant (Dean-4 of a large-size HEI) reflected that they realised they already had the IT systems in place, for example, they had Microsoft Teams already with them:

'It was not very challenging for us to go online; I mean, platform wise, the challenge was with the pedagogy. What you had to do face to face, now you have to do online, sitting in a room. We worked hard on that, we provided tablets to faculty members and we conducted a week-long workshop on pedagogy'.

Some of their students continued to stay in the hostel, while the HEI created a plan to get students back to campus if they wanted. They launched a survey to determine whether the students had access to the internet and space to work. ii) Digital examinations \& evaluation:

The digital evaluation system is being practiced in a majority of the HEIs in the country particularly during

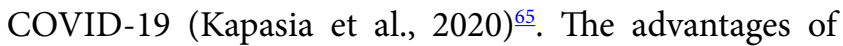
online examination could be its accuracy and the capacity of delivering fast results. On the other hand, HEIs are facing several complications to manage the online examination and its feasibility. They are taking enormous efforts to detect and stop cheating possibilities by the students during the online examinations (Gamage et al., $2020)^{66}$. To this effect, some HEIs have used the online proctored examination (OPE) tool to conduct admission tests, evaluations and final examinations during the

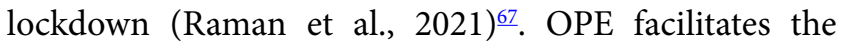
proctor to monitor the examination remotely and view the student distantly live (Nie et al., 2020) ${ }^{68}$. The UGC had also issued guidelines from time to time for the completion of courses, conducting of examinations etc., (UGC, 2020) ${ }^{69}$.

A participant (FM-1 of a large-size HEI) from HEI mentioned that they experimented with new and flexible ideas to for evaluation of the students. The participant voiced:

'Some exams happened in the examination hall, and some exams were held online. And it is again hybrid model that will be adopted for the final exam. They will be taking exams from their homes, and it will be a pen and paper exam. Then, they will submit answers online. However, the online mode may be still possible in metro cities and urban areas, but I am concerned about the rural areas'.

The voice reveals the practice of the hybrid model for online teaching as well as internal and final examinations of the students in the higher education sector. The participant also expressed anguish about the digital divide, particularly in remote rural areas. It calls for a proactive approach from the government and institutions to provide internet connectivity to needy students (Roy \& Roy, 2021; UNESCO IESALC, 2020) $)^{70,3}$.

Another participant (Dean-8 of a medium-size HEI) remarked:

'Digitisation has already started with COVID-19. We are into online. We conduct classes and assessment through the digital mode.

The participant further elaborated that the HEI could conduct doctoral viva voce's online. The examiner sits say at place A, while the candidate is at position B, and the guide is at place $\mathrm{C}$. All others attend from different locations. 


\section{iii) Digital administration}

During the pandemic, HEIs have been using blended working systems in the administrative functions of universities (Anane et al., 2020) ) $^{71}$. In some Governmentfunded HEIs, there are no vigorous initiatives to implement the automation system and the use of ICT services. It is possibly due to various constraints, including the university employees' lack of motivation to go digital.

As stated by a participant (VC-8 from a largesize HEI) that HEIs are yet to use digital technologies appropriately. Some HEIs lag in it. They still rely on paper and pen processes. It delays processes. What should have been over in a day takes many more days. S/he further commented:

'Considering COVID-19 and the pandemic situation, now we have to become digital as early as possible. And that will bring more transparency. Even some people hardly know computer operations in my organisation. Many feel they are about to retire after one or two or three years. They are reluctant to go for the training and feel (अब्बीक्याकरनाहै) what we have to do now, and I am going to retire now?

The participant highlights the importance of digital systems (Jha et al., 2020) ${ }^{72}$. More importantly, the HEIs need to motivate their employees to use existing digital systems.

Another participant (Dean-6 from a large-size public HEI) stated:

'Most staff members are not well-versed with digital systems. These employees insist on paperwork. It becomes another major hindrance.'

It demonstrates the existence of resistance in organisations against the use of digital systems. When employees cannot manage the digital systems, it becomes challenging for them to work faster to deal with challenging times like COVID-19. While HEIs have managed without digital systems pre COVID-19 to some extent, however there is no choice left for them but to use digital systems for education during and post COVID-19. Adaptation to digital systems has become a necessity and digital tools like Enterprise Resource Planning (ERP), Microsoft Teams, Google Class rooms, Moodle, Zoom, Webex, MS teams, Google; Office 365 (word, excel, power point, forms, one drive etc., a part and parcel of the academia.

However, a few HEIs have demonstrated their ability and efficiency. They have effectively managed the COVID-19 situation and embraced the use of digital systems efficiently.
A participant (Dean-4 of a large-size private HEI) believes that the digital system is going to stay. It may work with physical and social spaces. S/he said:

'But at the end of the day, you know, COVID-19 will go away, and yes, we will reclaim the physical space. For example, if things are digitised, people will find an easier way to communicate.

Such a statement underlines the importance of digital systems in HEIs even in the post COVID-19 scenario. Moreover, the voice points to a likely fusion of virtual and face to face environments in campuses.

Another participant (Dean-7 of a medium-size HEI) described that his/her campus was already a digitally governed one. They use an innovative card system to run the canteen. This has reduced the turn around time significantly. The participant gave some more instances of digitalisation. S/he observed:

'It was routine for about 50 years, and no one even thought about it. But now you just flash your card, and you don't have to worry about any currency or coin. Another case, our entrance exams used to be graded by hand and proctored in person. People used to go to 26 centres all over India, carry heavy boxes of exam papers, sit down in a particular University for three hours to wait to bring it back on a flight. Now, these things are outsourced to TCS (Tata Consultancy Services)to do it electronically'.

Digital systems have also increased productivity and managed scheduling efficiently. Vice Chancellor-1, of a small-size HEI) commented:

'Digital technology has improved efficiency. For example, I don't have to travel much. It has also increased productivity. You can simultaneously attend three-four conferences a day'.

The voice reveals the benefits of organising and attending academic events through the online mode. Although organising physical events like conferences, workshops etc. has its own benefits, but this has its own challenges too which include ensuring physical attendance, hassles of the organisation, time and financial constraints etc. While organising such academic events digitally or online has several benefitsincluding a) one could attend multiple events during a day b) save the time and hassles of travel $c$ ) it encourage much more participants and also the quality of participants since people can attend from distant places as well as other parts of the world d) requires less funding to organise the events (Pandit, 2021) 


\section{Conclusion}

In this research study, we have analysed the voices of various significant stakeholders belonging to a heterogeneous set of Indian HEIs delving into how they use digital systems to cope with the problems that have emerged during the COVID-19. The data generated two broad themes for study: HEIs response to COVID-19 and the importance of digital systems during COVID-19. The study delineates multiple dimensions of institutional responses to the challenges that have arisen in the course of the COVID-19 pandemic. It discusses the nature of adopting digital systems by HEIs, and narrates diversities in practices. 'The pandemic showed us how important it is to ensure digital connectivity for all in order to be even a basically functional society. Those who could shop online could ensure basic needs. Children who could log onto the internet studied, while the remaining missed an entire year's education' (Parikh, 2021) ${ }^{\frac{73}{3}}$. Interpreting the voices that we have collected as our research effort to contribute to the understanding on the subject, we see a clear prospect of them supporting and augmenting the usage of digital systems in academic and administrative processes. However, not all of higher education institutions are equally adept at embracing this change. Some are at a nascent stage of adaptation, while some are more evolved users. A few institutions are at the forefront, thanks to their early adoption of digital systems in day-to-day functioning. Some institutions that are new to the system are likely to progress to the next level of adoption. In a country like India, where enrolment in higher education is still lower than the desirable level, a creative policy that promotes digitalisation could very well emerge as a catalyst in facilitating and overcoming constraints like distance and affordability.

The flexible governance systems in HEIs have played a significant role during the pandemic crisis, enabling them to make quick decisions for smooth functioning. Our study and analysis demonstrates that online and digital systems have played a crucial role in mitigating the damage caused due to the pandemic. While all participants in the study narrated experiences regarding the different types of digital techniques adopted by various HEIs, the converging aspect is the need for up-grading digital infrastructure in the future. For example, COVID19 has pushed all of them to go wholly digital and operate as an Open Distance Learning System. However, some narratives refute that theory that the online system can ever replace physical campuses. Further, voices converge on the possibility of HEIs adapting themselves to a hybrid model that consists of both digital and physical systems (Muthuprasad et al., 2021) ${ }^{74}$.

The voices reported and discussed in this paper reflect how academic leadership responds to a crisis. However, it does not resonate with the thoughts on resuming social and intellectual spaces, which have vanished due to pandemic, in the campuses. From the point of view of operationality, the digital model got the academic systems up and running. The efficiencies emanating from it elude some critical questions on the digital divide and its ensuing inequalities. While the mode remains a technical aspect of operation, whether it substitutes the advantages of a socio-physical system of campus teaching and learning is doubtful.

\section{Acknowledgement}

Our sincere thanks to all the participants who participated in this study for kindly sharing their experiences.

\section{References}

1. Crawford, J., Butler-Henderson, K., Rudolph, J., Malkawi, B., Glowatz, M., Burton, R., Magni, P., \& Lam, S. COVID19: 20 countries' higher education intra-period digital pedagogy responses. Journal of Applied Learning \& Teaching. 2020; 3(1):1-20.

2. Mittal, P. Impact of COVID-19 on higher education in India. In Regional \& National Perspectives on the Impact of the COVID-19 on higher education. International Association of Universities. 2020; pp. 18-21.

3. UNESCO IESALC. COVID-19 and higher education: Today and tomorrow. Impact analysis, policy responses and recommendations. 2002.

4. Bordoloi, R., Das, P., \& Das, K. Perception towards online/ blended learning at the time of COVID-19 pandemic: an academic analytics in the Indian context. Asian Association of Open Universities Journal. 2021; 16(1):41-60.

5. Schilirò, D. Digital transformation, COVID-19, and the future of work. MPRA. 2021; Paper No. 108817.

6. Antonopoulou, H., Halkiopoulos, C., Barlou, O., \& Beligiannis, G. N. Transformational leadership and digital skills in higher education institutes: during the COVID-19 pandemic. Emerging Science Journal. 2021; 5(1): 1-15.

7. Dhawan, S. Online learning: A panacea in the time of COVID-19 crisis. Journal of Educational Technology Systems. 2020; 49(1): 5-22. 
8. Khan, M. A., Nabi, M. K., Khojah, M., \& Tahir, M. Students' perception towards e-learning during COVID-19 pandemic in India: An empirical study. Sustainability. 2021; 13(1): 57.

9. Swayam Central. Swayam Central. Retrieved April 8, 2021, from https://swayam.gov.in/

10. National Digital Library of India. (2021). https://ndl.iitkgp. ac.in/.

11. Shodhganga: A reservoir of Indian theses @ INFLIBNET. Shodhganga. Retrieved April 8, 2021, from https:// shodhganga.inflibnet.ac.in/

12. eGyanKosh (2021). eGyanKosh. Retrieved April 8, 2021, from http://egyankosh.ac.in/

13. Gyandarshan. (n.d.). Retrieved April 8, 2021, from https:// www.ignouonline.ac.in/gyandarshan/Ignou. counter create hit. (2021). https://www.ignouonline.ac.in/gyandarshan/.

14. E-PGPathshala. (2015). E-PGPathshala. Retrieved April 8, 2021, from https://epgp.inflibnet.ac.in/

15. Biswas, S., \& Sarkar, M. MOOC: Challenges \& Prospects in Indian Higher Education, Journal of Information and Computational Science. 2020; 10(2): 1015-1024.

16. Meena, M.K. Living the teaching life in a time of COVID19. CEA Critic, 2020; 82(3): 266-270.

17. Zhang, W., Wang, Y., Yang, L., \& Wang, C. Suspending ClassesWithout Stopping Learning: China's Education Emergency Management Policy in the COVID-19 Outbreak. Journal of Risk and Financial Management.2020; 13(55): 1-6.

18. Arora, A. R., \& Gupta, R. A Tale of Two States: Analyzing the State of Higher Education in Kerala and Karnataka. Journal of Education and Practice. 2021; 12(10): 1-5.

19. Cullinan, J., Flannery, D., Harold, J., Lyons, S., \& Palcic, D. The disconnected: COVID-19 and disparities in access to quality broadband for higher education students. International Journal of Educational Technology in Higher Education. 2021; 18(1): 1-21.

20. Mukerji, S. Online Education in the Developing World in the Pandemic Era: The Paradox of Disruption. HAPSc Policy Briefs Series. 2021; 2(1): 80-85.

21. Esteban Jr, Alfredo M. Digital Divide in Times of Pandemic among Teacher Education Students.Open Access Library Journal. 2021; 8:e7323.

22. Reddy, A. Bheemeshwar, Jose, Sunny \& Vaidehi, R. Of Access and Inclusivity: Digital Divide in Online Education. Economic and political weekly. 2020; 55: 23-26.

23. Odriozola-Gonzáleza P, Planchuelo-Gómezb A, Irurtiaa MJ, de Luis-Garcíab R. (2020) Psychological effects of the COVID-19 outbreak and lockdown among students and workers of a Spanish university. Psychiatry Research. 2020; 290: 113108.

24. Xiang YT, Yang Y, Li W, Zhang L, Zhang Q, Cheung T, et al. Timely mental health care for the 2019 novel coronavirus outbreak is urgently needed. Lancet Psychiat. 2020; 7: 228-9.

25. Bisht, B., Sharma, D., \& Kaur, N. Online Classes during COVID-19 Pandemic: Anxiety, Stress \& Depression among University Students. Indian Journal of Forensic Medicine \& Toxicology. 2021; 15(1): 186-189.

26. Wang C, Pan R, Wan X, Tan Y, Xu L, Ho CS, et al. Immediate psychological responses and associated factors during the initial stage of the 2019 coronavirus disease (COVID囚19) epidemic among the general population in China.Int J Environ Res Public Health. 2020; 17(5): 1729.

27. Mishra, L., Gupta, T., \& Shree, A. Online teaching-learning in higher education during lockdown period of COVID-19 pandemic. International Journal of Educational Research Open. 2020; 1: 100012.

28. Sahu, P. Closure of universities due to coronavirus disease 2019 (COVID-19): impact on education and mental health of students and academic staff. Cureus. 2020; 12(4): e7541. http://dx.doi.org/10.7759/cureus.7541

29. Son, C., Hegde, S., Smith, A., Wang, X., \& Sasangohar, F. Effects of COVID-19 on college students' mental health in the United States: Interview survey study. Journal of Medical Internet Research. 2020; 22(9): 21279.

30. Rai, S., Akhtar, Z., Singh, K. K., Bhatt, M. L. B., Verma, S. K., \& Kar, S. K. Academic loss-related anxiety among college students during COVID-19 pandemic. Indian Journal of Health Sciences and Biomedical Research (KLEU). 2021; 14(2): 239-244.

31. Clabaugh, A., Duque, J. F., \& Fields, L. J. Academic stress and emotional well-being in united states college students following onset of the COVID-19 pandemic. Frontiers in Psychology. 2021; 12:628787. http://dx.doi.org/10.3389/ fpsyg.2021.628787

32. Rogowska, A. M., Kuśnierz, C., \& Bokszczanin, A. Examining anxiety, life satisfaction, general health, stress and coping styles during COVID-19 pandemic in Polish sample of university students. Psychology Research and Behavior Management. 2020; 13: 797-811. https://doi. org/10.2147/PRBM.S266511

33. Hassan, N. Online teaching-learning during COVID-19 pandemic: students' perspective. The Online Journal of Distance Education and e-Learning. 2020; 8(4): 202-213.

34. Bania, J., \& Banerjee, I. (2020). Impact of COVID-19 Pandemic on Higher Education: A Critical Review. Higher Education after the COVID-19 crisis. 2020; 1-12.

35. Al Lily AE, Ismail AF, Abunasser FM and Alhajhoj RH. Distance education as a response to pandemics: coronavirus and Arab culture. Technology in Society. 2020; 63: 101317. http://dx.doi.org/ 101317.

36. Besser A, Lotem S and Zeigler-Hill V. Psychological stress and vocal symptoms among university professors in Israel: 
implications of the shift to online synchronous teaching during the COVID-19 pandemic. Journal of Voice. 2020; S0892-1997(20)30190-9. http://dx.doi.org/10.1016/j.jvoice. 2020.05.028

37. Santamaría, M. D., Mondragon, N. I., Santxo, N. B., \& Ozamiz-Etxebarria, N. Teacher stress, anxiety and depression at the beginning of the academic year during the COVID-19 pandemic. Global Mental Health. 2021; 8: e14. http://dx.doi.org/10.1017/gmh.2021.14. eCollection 2021.

38. Babu, S. \& Ramaswamy, R. Higher Education Going Online: The challenges in India. Indian Academy of Sciences, Bangalore. 2021. pp. 1-163.

39. Ministry of Human Resource Development, Govt. of India (2020). National Education Policy 2020. New Delhi: MHRD.

40. Mathivanan, S. K., Jayagopal, P., Ahmed, S., Manivannan, S. S., Kumar, P. J., Raja, K. T., Dharinya, S. S., \& Prasad, R. G. Adoption of E-Learning during Lockdown in India. International Journal of System Assurance Engineering and Management. 2021; pp. 1-10. http://dx.doi.org/10.1007/ s13198-021-01072-4

41. Strielkowski, W. COVID-19 Pandemic and the Digital Revolution in Academia and Higher Education. Preprints 2020, 2020040290. http://dx.doi.org/ 10.20944/ preprints202004.0290.v1

42. Times Higher Education (THE). How COVID19 is improving university governance. https:// timeshighereducation.com/hub/pwc/p/how-covid-19. improving-university-governance. 2020.

43. Salmi, J. COVID's Lessons for Global Higher Education: Coping with the Present While Building a More Equitable Future. Lumina Foundation. 2020; pp. 1-93.

44. Cesco, S., Zara, V., De Toni, A. F., Lugli, P., Betta, G., Evans, A. C., \& Orzes, G. Higher education in the first year of COVID19: Thoughts and perspectives for the future. International Journal of Higher Education. 2021; 10(3): 285-294. http:// dx.doi.org/10.5430/ijhe.v10n3p285

45. Rameez, A., Fowsar, M. A. M., \& Lumna, N. Impact of COVID-19 on Higher Education Sectors in Sri Lanka: A Study based on South Eastern University of Sri Lanka. Journal of Educational and Social Research. 2020; 10(6): 341-349.

46. Sundarasen, S., Chinna, K., Kamaludin, K., Nurunnabi, M., Baloch, G. M., Khoshaim, H. B., \& Sukayt, A. Psychological impact of COVID-19 and lockdown among university students in Malaysia: implications and policy recommendations. International Journal of Environmental Research and Public Health. 2020; 17(17): 6206. https://doi. org/10.3390/ijerph17176206
47. Gressman, P. T., \& Peck, J. R. Simulating COVID-19 in a university environment. Mathematical Biosciences. 2020; 328: 108436. https://doi.org/10.1016/j.mbs.2020.108436.

48. Maqsood, A., Abbas, J., Rehman, G., \& Mubeen, R. The paradigm shift for educational system continuance in the advent of COVID-19 pandemic: Mental health challenges and reflections. Current Research in Behavioral Sciences. 2021; 2: 100011. https://doi.org/10.1016/j. crbeha.2020.100011.

49. Chakraborty, P., Mittal, P., Gupta, M. S., Yadav, S., \& Arora, A. Opinion of students on online education during the COVID囚19 pandemic. Human Behavior and Emerging Technologies. 2021; 3(3): 357-365. https://doi.org/10.1002/ hbe2.240

50. Garg, S. Artificial Intelligence and its Impact on Higher Education in Post COVID Era, University News, Association of Indian Universities. New Delhi, 2020; 58(36): 2-6.

51. Kummitha, H. R., Kolloju, N., Chittoor, P. \& Madepalli, V. Coronavirus disease 2019 and its effect on teaching and learning process in the higher educational institutions. Higher Education for the Future. 2021; 8(1): 90-107.

52. Rashid, S., \& Yadav, S. S. Impact of COVID-19 pandemic on higher education and research. Indian Journal of Human Development. 2020; 14(2): 340-343. https://doi. org/10.1177/0973703020946700

53. Jena, P. K. Impact of COVID-19 on higher education in India. International Journal of Advanced Education and Research (IJAER). 2020; 5(3): 77-81.

54. Aristovnik, A., Keržič, D., Ravšelj, D., Tomaževič, N., \& Umek, L. Impacts of the COVID-19 pandemic on life of higher education students: A global perspective. Sustainability. 2020; 12(20): 8438. https://doi.org/10.3390/ su12208438

55. Pandit, J. COVID-19: Impact \&Lessons Learnt. IGIDR Newsletter. 2012; pp. 36-39. www.econprismigidr. wordpress.com.

56. All India Survey on Higher Education (AISHE 2019-20). Ministry of Education. New Delhi: Government of India.

57. Creswell, J. W., \& Creswell, J. D. Research design: Qualitative, quantitative, and mixed methods approaches. Sage publications. 2017.

58. Braun, V., \& Clarke, V. (2006). Using thematic analysis in psychology. Qualitative Research in Psychology. 2006; 3(2): 77-101.

59. Seale, C. Validity, reliability and the quality of research. Researching Society and Culture. 2004; 2: 71-83.

60. Rossman, G., \& Rallis, S. F. Learning in the field: An introduction to qualitative research. Thousand Oaks, CA: Sage. 1998. 
61. Joshi, A., Vinay, M., \& Bhaskar, P. Impact of coronavirus pandemic on the Indian education sector: perspectives of teachers on online teaching and assessments. Interactive Technology and Smart Education. 2020.

62. UNDP. COVID-19 pandemic: Humanity needs leadership and solidarity to defeat the coronavirus. 2020.

63. Singh, R., \& Chanda, R. India's digital divide amid pandemic: A Review. Psychology and Education Journal. 2021; 58(2): 9344-9355.

64. Mishra, P., \& Shukla, S. Online Teaching in India during COVID-19: Opportunities and Challenges. 2021; 19: 20-28.

65. Kapasia, N., Paul, P., Roy, A., Saha, J., Zaveri, A., Mallick, R., \& Chouhan, P. Impact of lockdown on learning status of undergraduate and postgraduate students during COVID-19 pandemic in West Bengal, India. Children and Youth Services Review. 2020; 116: 105194. https://doi. org/10.1016/j.childyouth.2020.105194.

66. Gamage, K. A., Silva, E. K. D., \& Gunawardhana, N. Online delivery and assessment during COVID-19: Safeguarding academic integrity. Education Sciences, 2020; 10(11): 301. https://doi.org/10.3390/educsci10110301

67. Raman, R., Sairam, B., Veena, G., Vachharajani, H., \& Nedungadi, P. Adoption of online proctored examinations by university students during COVID-19: Innovation diffusion study. Education and Information Technologies. 2021; pp. 1-20. https://doi.org/10.1007/s10639-021-10581-5.

68. Nie, D., Panfilova, E., Samusenkov, V., \& Mikhaylov, A. E-learning financing models in russia for sustainable development. Sustainability. 2020; 12(11): 4412. https://doi. org/10.3390/su12114412

69. UGC. Report of the UGC committee on examinations and academic calendar for the universities in view of COVID19 pandemic and subsequent lockdown. April 2020.

70. Roy, B., \& Roy, A. Conducting examinations in India: Emergency, contention and challenges of students amidst
COVID-19 pandemic. Children and youth services review. 2021; 120: 105768. https://doi.org/10.1016/j. childyouth.2020.105768

71. Anane, G. K., Addo, P. K., Adusei, A., \& Addo, C. Impact of the COVID-19 Pandemic on the Work of University Administrators in Ghana. Journal of Commonwealth Council for Educational Administration \& Management, CCEAM. 2020; pp. 93-102.

72. Jha, Amit \& Singh, Ankur. Digital Education In India: Challenges and their Solutions. 2020. Digital Education In India: Challenges and their Solutions. https://doi. org/10.13140/RG.2.2.32600.32000.

73. Parikh, J. For a digital stimulus: Budget for growth and empowerment through digital access and connectivity. Times of India Blog. (2021, January 27). https:// timesofindia.indiatimes.com/blogs/toi-edit-page/for-adigital-stimulus-budget-for-growth-and-empowermentthrough-digital-access-and-connectivity/.

74. Muthuprasad, T., Aiswarya, S., Aditya, K. S., \& Jha, G. K. Students' perception and preference for online education in India during COVID-19 pandemic. Social Sciences \& Humanities Open. 2021; 3(1): 100101. https://doi. org/10.1016/j.ssaho.2020.100101

\section{Appendix 1. (Questions)}

The following are the key research questions.

- How have the Higher Education Institution coped with the COVID-19 challenges?

- Whether the HEI has put in place any hybrid models to deal with the COVID-19 challenges?

- Whether the digital solution will have a profound impact on the HEI's efficiency and the initiatives taken in this regard? 


\section{Appendix 2. Details of the participants}

\begin{tabular}{|c|c|c|c|}
\hline $\begin{array}{l}\text { Participant } \\
\text { Voice S. no }\end{array}$ & Code & $\begin{array}{l}\text { Participant } \\
\text { Designation }\end{array}$ & Type of HEI \\
\hline 1 & VC-1 & Vice-Chancellor & Deemed University \\
\hline 2 & $\mathrm{VC}-2$ & Vice-Chancellor & Central University \\
\hline 3 & Reg-2 & Registrar & State University \\
\hline 4 & $\mathrm{VC}-3$ & Vice-Chancellor & State Private University \\
\hline 5 & $\mathrm{VC}-4$ & Vice-Chancellor & Central University \\
\hline 6 & VC-5 & Vice-Chancellor & State University \\
\hline 7 & VC-6 & Vice-Chancellor & State University \\
\hline 8 & Dean-1 & Dean & Institute of National Importance \\
\hline 9 & Reg-3 & Registrar & Institute of National Importance \\
\hline 10 & Dean-2 & Dean & State Private University \\
\hline 11 & Reg-4 & Registrar & Institute of National Importance \\
\hline 12 & Dean-3 & Dean & State Private University \\
\hline 13 & FM-1 & Faculty Member & Central University \\
\hline 14 & Reg-1 & Registrar & Institute of National Importance \\
\hline 15 & Dean-3 & Dean & State Private University \\
\hline 16 & VC-7 & Vice-Chancellor & Deemed University \\
\hline 17 & VC-9 & Vice-Chancellor & State University \\
\hline 18 & Reg-3 & Registrar & Institute of National Importance \\
\hline 19 & Dean-4 & Dean & State Private University \\
\hline 20 & FM-1 & Faculty Member & Central University \\
\hline 21 & Dean-8 & Dean & Institute of National Importance \\
\hline 22 & VC-8 & Vice-Chancellor & State University \\
\hline 23 & Dean-6 & Dean & State University \\
\hline 24 & Dean-4 & Dean & State Private University \\
\hline 25 & Dean-7 & Dean & Deemed University \\
\hline 26 & VC-1 & Vice-Chancellor & Deemed University \\
\hline
\end{tabular}

